\title{
An interest-rate-spread-based measure of Turkish monetary policy
}

\section{Hakan Berument, Nildag Basak Ceylan \& Burak Dogan}

To cite this article: M. Hakan Berument, Nildag Basak Ceylan \& Burak Dogan (2014) An interestrate-spread-based measure of Turkish monetary policy, Applied Economics, 46:15, 1804-1813, DOI: $10.1080 / 00036846.2014 .884703$

To link to this article: http://dx.doi.org/10.1080/00036846.2014.884703

册 Published online: 18 Feb 2014.

Submit your article to this journal $\pi$

Џll Article views: 192

Q View related articles ¿

View Crossmark data ¿

4 Citing articles: 2 View citing articles ๘ 


\title{
An interest-rate-spread-based measure of Turkish monetary policy
}

\author{
M. Hakan Berument ${ }^{\mathrm{a}, *}$, Nildag Basak Ceylan ${ }^{\mathrm{b}}$ and Burak Dogan ${ }^{\mathrm{c}}$ \\ ${ }^{a}$ Department of Economics, Bilkent University, Ankara 06800, Turkey \\ ${ }^{\mathrm{b}}$ Department of Banking and Finance, Yildirim Beyazit University, Ankara \\ 06690, Turkey \\ ${ }^{\mathrm{c}}$ Research and Fund Management Directorate, Central Bank of the Turkish \\ Republic of Northern Cyprus, Bedrettin Demirel Cad., Lefkoşa, KKTC, Via \\ Mersin 10, Cyprus, Turkey
}

\begin{abstract}
A coherent method to measure the effectiveness of a monetary policy improves the monetary authority's management capacity and renders the possibility of applying sound policies prior to and during a crisis. The trend in employing complicated and ambiguity-bearing unconventional monetary tools in the aftermath of the 2008 crisis has increased the value of such a method. The aim of this article is to introduce a coherent and consistent monetary policy evaluation method for Turkey. Accordingly, we suggest that innovations in the spread between overnight interest rates and Treasury auction interest rates are informative for exchange rate, output, and prices. Empirical evidence for this identification reveals that positive innovation in spread (implying a tight monetary policy measure) decreases output temporarily, permanently decreases prices, and appreciates local currency. This result is also robust to alternative specifications.
\end{abstract}

Keywords: monetary policy evaluation; interest rate spreads; business cycles

JEL Classification: E52; E58; E32

\section{Introduction}

Finding a proper measure and evaluation method for monetary policy is still among the most tempting pursuits in the economic literature. Conventional pure monetary policy suggests that central banks can utilize interest rate tools by directly adjusting short-term funding rates and by engaging in open-market operations or regulating reserve requirement ratios, which in turn affect market liquidity and long-term interest rates. However, the recessionary environment of the post-2008 crisis forced central banks to apply unconventional policy tools that require accommodative measures of policy effectiveness. The purpose of this article is to suggest using the innovations in spread between overnight interest rates and Treasury auction interest rates as an indicator of the stance of the Turkish monetary condition. This variable is informative for exchange rate, output, and prices.

\section{Drawbacks of conventional measures}

Various measures are generally accepted in the literature to observe monetary policy effectiveness. For instance, sizes of monetary aggregates, such as M1 or M2, are used as measures of monetary policy or as measures of liquidity. However, the relationship between money and income may not be stable (see, for example, Friedman and Kuttner, 1992).

*Corresponding author. E-mail: berument@bilkent.edu.tr

The views expressed here do not necessarily represent the official position of the Central Bank of the TRNC. 
Nonborrowed reserves (NBRs), which measure the difference between a bank's total reserves and borrowed reserves (from the central bank), have been introduced as a variable that can be more easily controlled than M1 and M2. However, Bernanke and Mihov (1998) found no statistically significant empirical evidence that US monetary policy was properly measured by NBRs except for during the 1979-1982 period.

Interbank or central bank funding rates have also been frequently used as monetary policy indicators. Even if their innovation in short-term interest rates well explains output behaviour, the use of this variable produced inconsistent estimates on prices and exchange rates compared to expectations (puzzles). In the literature, Laurent (1988) recognized that short-term rates are under the influence of the central bank by their manipulative power over the funding rate. On the other hand, although funding rate may affect many monetary aggregates, there is no straightforward reason why the monetary authority's funding rate intervention should directly affect economic activity.

The problem is the interdependence of monetary aggregates and the real economy bridged by the financial sector. This situation creates endogeneity for monetary policy decisions. For this reason, it is not an easy task to design monetary policy, especially when seeking additional targets for price stability, such as financial stability. Even when controlling only for prices, price stability increases eagerness in the search for yield, and financial institutions become involved in risky investments through increasing leverage and currency/maturity mismatches. Therefore, distilling the pure effects of monetary policy is quite knotty. Mishkin (2011) noted that theoretical and practical economists try to impose financial frictions into general equilibrium models to account for interdependence. Referring to Johnson (1988), Woodford (1994) stated that monetary policy alterations should be transmitted to financial market prices to effect broader price measures and thus impact the real economy.

\section{Interbank-Treasury spread as a measure of monetary policy}

In numerous studies, spread notion has been defined to correlate with different macroeconomic variables. Many of these studies have taken the spread between short- and long-term interest rates according to a most reasonable explanation, which can be summed up as the relative insensitiveness of longer-term interest rates to monetary policy. For instance, Laurent (1988) defined spread as the difference between the 20 -year bond rate and the federal funds rate, while Stock and Watson (1989) defined it as the difference between 1- and 10-year Treasury bond rates. Bernanke (1990) suggested various spread definitions, such as the difference between the long-term Baa credit rating corporate bond rate and a 10 -year Treasury bond rate or as the difference between the overnight funds rate and a 10-year Treasury bond rate, and stated that the commercial paper-Treasury bill spread emerged as the best predictor. More recently, McCallum (2005) used one-period and two-period bond interest rates, whereas Nautz and Offermanns (2008) took the difference between the Eonia and 3-month Euribor interest rates to measure the European Central Bank's monetary policy. Berument (2007) introduced a slightly different spread definition, comparing currency depreciation rate with the short-term interest rate for Turkey.

We introduce the spread between interbank and Treasury auction rates as a measure of monetary policy. The interbank rate is a measure of the overnight funding rate for the financial system and the Treasury auction rate is a measure of the return on investment in the long run. We assume that private sector expectations are based on a comparison of the monetary policy rate (which is interbank rate here) with the Treasury auction rate for at least three reasons: (1) the comparison contains enough expected yield information to encompass most of the available determinants; (2) the bond market can be complementary and supplementary to other financial markets, depending on the given economic conditions, and thus accepted as the financial friction; and (3) the comparison is simple to observe for policy makers and market participants alike. All in all, Treasury yields, especially benchmark bond yields, affect borrowing costs, which in turn affect level of investment, equity values, consumption, employment, and finally, output.

The above explains our Treasury yield choice. Yet there may be another question: Why do we use the Treasury auction interest rate but nothing else for Turkey?

First, we cannot use constant maturity interest rates because the Turkish bond market is not as deep as moredeveloped markets such as the US; there is thus no constant maturity benchmark note as employed in similar studies on the US economy.

Second, we could have taken the benchmark bond rather than the average of the Treasury auction rates, as that bond is frequently used in similar studies dealing with US data. Indeed, there exists a benchmark note in the Turkish bond market according to which other bonds' performances can be measured. However, this benchmark bond has a shorter maturity and can be changed at any time with any other bond, ${ }^{1}$ which raises the problem

\footnotetext{
${ }^{1}$ A Treasury bond with a maturity date of 20 February 2013 was the benchmark note at the end of the data time span of this study; however, while this article was being drafted, the bond was changed to one dated 5 March 2014.
} 
of volatile maturity. It must also be noted that the Treasury determines maturity along with interest rate. As the Treasury changes the benchmark bond, it then also changes the prevailing interest rate. Eventually, if we use the benchmark bond with the interbank rate to obtain the spread, when the Treasury changes the benchmark it could be signalling a monetary policy shift when in fact it is not.

Then the question becomes: Why do we use the Treasury auction rate if we cannot use the benchmark?

By definition, auction maturity changes in each auction. Using Turkish Treasury auction data between 1988 and 2004, Berument and Yucel (2005) reported a statistically significant stable negative relationship between maturity and auction interest rate. Thus, as auction maturity increases, interest rate decreases. The authors argued that when the economy faces an adverse shock, the Treasury is willing to lower the maturity for its borrowing, and increase the interest rate, rather than relying on pure interest rates. Otherwise interest rate would increase too much. Because this relation is stable, auction interest rate alone captures the credit cost for the depository institution. Thus, we may use auction interest rates alone rather than interest rates and maturity together.

Treasury bond rates are the main interest rates that derive the asset sides of financial institutions. The key factor that correlates the central bank funding rate and auction rate is the amount of government bonds that financial institutions hold on their balance sheets. The government bonds-to-total assets ratio of Turkey's commercial banks' consolidated balance sheet was $26.4 \%$ on average between 2002:12 and 2011:07² ; therefore, interest rate gains from the bonds constitute a significant share in banks' profits. While auction interest rates in the primary market are highly correlated with secondary bonds' market rates through expected yields, the rates on banks' bond holdings directly affect credit and deposit rates. Moreover, relative movements in funding rates and capital gains are determinant for private banks to supply credit to investors and households. Thus, the link between monetary policy and real economy is bridged, and henceforth, we define the spread as 'interbank rate minus Treasury auction rate.' A higher overnight rate relative to auction rate (with all other factors unchanged) indicates a tighter monetary policy, and because the central bank provides a lower level of liquidity to the market compared to what the market accepts, we normally expect output and prices to decline in the subsequent periods.

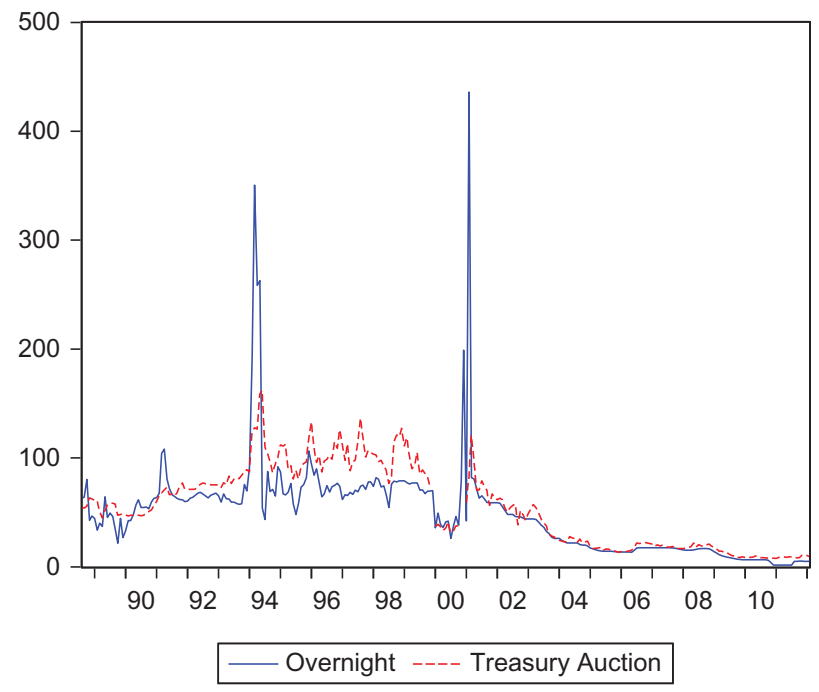

Fig. 1. Interbank overnight interest rates and Treasury auction interest rates

The spread between overnight rates and Treasury auction interest rates bunches the cost and return of credit for the financial system. Figure 1 shows the trajectory of these two rates for Turkey. Except for a few crisis periods, Treasury rates have always exceeded the central bank's policy rate. Whenever the monetary authority decides to alter interest rates (by directly shifting the short-term policy rate or changing the reserve requirement policy) the depository institutions determine their new positions by comparing the new interest rate with longer-term credit facilities.

In Section II, we present the model within the VAR methodology. We discuss the data in Section III, and in Section IV we present the empirical evidence and provide a set of robustness analyses as well as explore major challenges (i.e., puzzles). We conclude the article in Section V.

\section{Empirical Methodology}

In identifying the effects of policies exclusive to a central bank, it is important to set policy indicators that are largely insensitive to other variables. To do this, we set up a VAR model as suggested by Christiano et al. (1999) and the references cited therein.

The economy is assumed to be in the form of a linear stochastic dynamic model. Without considering the constant term, one may write:

\footnotetext{
${ }^{2}$ Data gathered from Turkey's Banking Regulation and Supervision Agency's data base: http://ebulten.bddk.org.tr/AylikBulten/ Gelismis.aspx
} 


$$
\Gamma(L) y=\varepsilon
$$

where the lag operator in the matrix polynomial $\Gamma(L)$ is denoted by $L$, the data vector is denoted by $y$, and the vector of interpretable disturbances is shown by $\varepsilon$. It is assumed that for $s>0, \varepsilon(t)$ and $y(t-s)$ are uncorrelated in determining the model and data vector. It is also assumed that the coefficient on $L^{0}$, which in $\Gamma(L)$ is $\Gamma_{0}$, is nonsingular. In the case that Equation 1 holds, having considered the stochastic assumptions on $\varepsilon$ and $y$, the matrix containing the coefficients denoted as $B(L)$ is reduced to a VAR:

$$
y(t)=B(L) y(t)+u(t)
$$

that is, related to $\Gamma$ with the following equation:

$$
I-B(L)=\Gamma_{0}^{-1} \Gamma(L)
$$

In addition, the covariance matrix shown as $\Lambda$ of $\varepsilon$ has a relation with the covariance matrix $\Sigma$ of $u$ with the following equation:

$$
\Gamma_{0} \Sigma \Gamma_{0=}^{-1} \Lambda
$$

where $\Gamma_{0}$ is a nonsingular matrix that is normalized so that it has ones on the diagonals and shows the contemporaneous relationships between the variables in the vector $y$ ( $t)$. If no a priori conditions exist on $\Gamma(L)$, there exist also no conditions on $B(L)$. Depending on whether other parameters are integrated or concentrated out, the likelihood, which is a function of $\Gamma_{0}$ and $\Lambda$, is dependent on the data through $S$, which is the estimated covariance matrix for $u$, that is, the reduced-form residuals. If restrictions exist on $\Gamma_{0}$ that make it identifiable, it is possible to find the flatprior posterior mean or mode using a nonlinear maximization or integration that depends only on $S$. If one has tried a broad range of identification schemes on $\Gamma_{0}$, it is not necessary to apply the identifying restrictions in the formation of $S$ or to restore $S$. This conceptual structure is useful because it does not involve any restrictions that include $\Gamma_{s}$ with $s>0$, although the knowledge we have for $\Gamma_{s}$ for $s=0$ is scarce and for any $s>0$ it is none. For now, it is better not to treat our information on $\Gamma_{0}$ and $\Lambda$, and carry the informal information on $\Gamma_{s}$ for $s>0$. We will examine the estimated systems where formal identifying restrictions are put on $\Gamma_{0}$ and $\Gamma$ in the VAR model. One may also visit Sims and Zha (2006) for further discussion of this issue.

We make two basic assumptions regarding the model. First, exchange rate is exogenous for the domestic economy at a given time period but interacts with other variables with a lag. This is a reasonable assumption because Turkey is a small open economy, and thus short-term capital inflows are the main driver of exchange rates and move according to the relative conditions of the rest of the world. Thus, in our monthly data, we assume the Central Bank of the Republic of Turkey (CBRT) responds to contemporaneous developments in the exchange rate, rather than leading it. The period where the CBRT had depreciated the local currency with a predetermined path (or the period that was well predicted by the market) ended in 2001:03. Therefore, in this period, the depreciation rate is also pre-determined to spread (see Berument (2007) for discussion on the issue). Thus, even if the CBRT was influential in setting the exchange rate for the pre-2001:03 period, exchange rate would still precede the spread.

Second, we assume the interest rate spread is exogenous for other macroeconomic variables such as income and prices at a given period. That is, parallel to Leeper et al. (1996) and Sims and Zha (2006), innovation in spread leads to innovation in income and prices rather than the opposite at a given time. This is a reasonable assumption because a central bank cannot observe the real level of prices and output at the time of decision due to data-gathering trouble, and it is more likely that current interest rate affects current output and prices. However, all variables in the system interact with each other with a lag.

To identify the system, we need to consider the identifying restrictions on $\Gamma_{0}$ and $\Lambda$. Thus, parallel to Leeper et al. (1996) and Sims and Zha (2006), we employ the Choleski decomposition and assume that there is no contemporaneous effect of monetary policy on disturbances in the general price level or the level of income. We use this restriction because no contemporaneous data exists for these variables when policy decisions are being made. If we place the monetary policy variable after the output and prices, we would have the extreme information that the central bank knows both variables before they set their policy actions. If we had been using quarterly data, then we could assume that the central bank could observe monthly data within each quarter (or at least the industrial production of the first month and the price levels of the first 2 months) before they set their policy rate, and then placing income and prices before the policy rate would make more sense. One may look at Christiano et al. (1999) for discussion on this issue.

\section{Data}

The monthly Treasury auction interest rate is the weighted average of each auction's interest rate for the corresponding month, excluding consumer price index (CPI)-linked 
or foreign exchange (FX)-denominated or FX-linked auctions. $^{3}$

Industrial production is taken as a measure of income; $\mathrm{CPI}$ is taken as a measure of prices. The exchange rate (exchange) is the official exchange basket that the CBRT has been following in its operations: 0.5 USD +0.5 Euro. ${ }^{4}$ The interbank rate is the CBRT's overnight interbank rate. Money $(m)$ is M2 plus Repo volume. All data are available from the CBRT's data delivery system. ${ }^{5}$

The sample starts in 1988:08 due to data availability and ends in 2011:07, when the CBRT abandoned overnight rates as a policy rate and switched to over-week rates. However, we extend the data span to 2012:07 in a later stage of the analysis by using the overnight borrowing cost. During the estimation, we include 11 monthly dummies to account for seasonality and five intercept dummies to account for financial crises. The intercept dummies take the value of 1 for the corresponding month and 0 otherwise.

\section{Empirical Evidence}

In this section, we present the results obtained from the set of VAR models, whose distinctive features comprise including the additional explanatory variables in the model (keeping the spread measures in each model) or the length of the data span. We interpret the impulse responses of our basic model, where the variables are ordered as exchange rate (Exchange Rate); the spread between the overnight interbank interest rate and the Treasury auction interest rate (spread); industrial production (IP) as a measure of income; and CPI as a measure of prices. All variables enter the system in their logarithms except for spread. As the Bayesian Information Criteria suggests, the lag order is 1 . To account for seasonality, we include 11 monthly dummies. To account for financial crises, we include dummies for 1994:04, 1994:05, 2000:11 2001:02, and 2001:03.

We assess the results and present graphs for the impulse responses generated by the same models. Figure 2 displays the estimated impulse responses in the wake of a contractionary monetary policy, depicted as a positive innovation in the interbank-Treasury auction interest rate spread in the macroeconomic variables considered. We report impulse responses for an 18month horizon. The middle line shows the median of the draws and the other two lines show the confidence intervals at the $95 \%$ level.

Identifying monetary policy within a VAR framework is challenging. Impulse responses, that is, the time path of the model's dependent variables, enclose a set of well-known puzzles, when there is an exogenous change in another variable. Two of these puzzles are closely related to monetary policy stance. Accordingly, tight monetary policy, measured with a higher interest rate, may give higher instead of expectedly lower prices (price puzzle), and eventually depreciate local currency rather than appreciating it (exchange rate puzzle). One may visit Kim and Roubini (2000) for a further discussion of these issues. In our specification, a positive shock to spread decreases (appreciates) exchange rate. Thus, we do not see the exchange rate puzzle. Second, the shock to spread persists for 5 months in a statistically significant fashion. The persistence of monetary policy is something expected. Output tends to decrease for 3 months and then return to its initial level. Eventually, tight monetary policy decreases prices. Thus, we do not see the price puzzle, either. Moreover, the decrease in prices is persistent.

Further elaborating on the basic model, we first make a new specification and end the sample data as of 2011:07. We do this because on 3 August 2011, the CBRT publicly declared the over-week rate as its new policy tool, dropping the overnight rate. It also announced that, whenever it deemed necessary, it might not provide liquidity to the market on the normally scheduled auction dates. When an auction was not called, these dates were called 'exceptional days' and indeed, the CBRT did not fund the market on those days. Ultimately, there is a cliff between market overnight and official over-week rates in the exceptional days' data. Nevertheless, Fig. 3 shows the same estimate by replacing the overnight rate after 2011:08 with the effective Interbank Overnight Funding rate, extending the sample until 2012:07. By considering the unusual rate divergence on the

\footnotetext{
${ }^{3}$ The Treasury opens auctions for various maturities each month. Here, we disregard these different maturities for each auction when we calculate the Treasury auction interest rate for each month. Therefore, the auction interest rate that we use is a mixture of several 'forward rates,' which is implicit in the term structure of interest rates with different maturities. In other words, the auction interest rate variable is a pooled time series of forward rates with different maturities. Calvo and Guidotti (1992) and Missale and Blanchard (1994) argued that there is an inverse relationship between auction interest rate and maturities. Empirical evidence from Turkey suggests that this relationship does exist (see Berument and Yucel, 2005). Therefore, the 'variable-maturity' auction interest rate variable that we use is a monotonic transformation of the 'constant-maturity' auction interest rate that one might use to measure fiscal policy, and thus we can use the (variable-maturity) auction interest rate as an indicator of fiscal policy, as suggested by the envelope theorem.

${ }^{4}$ The Euro was introduced in 1999. For the period that we do not have data, we use the official convention between the Euro and the Deutsche Mark (DM) and use the basket as 0.5 USD + 0.974027 DM.

${ }^{5}$ http://evds.tcmb.gov.tr/cbt.html
} 

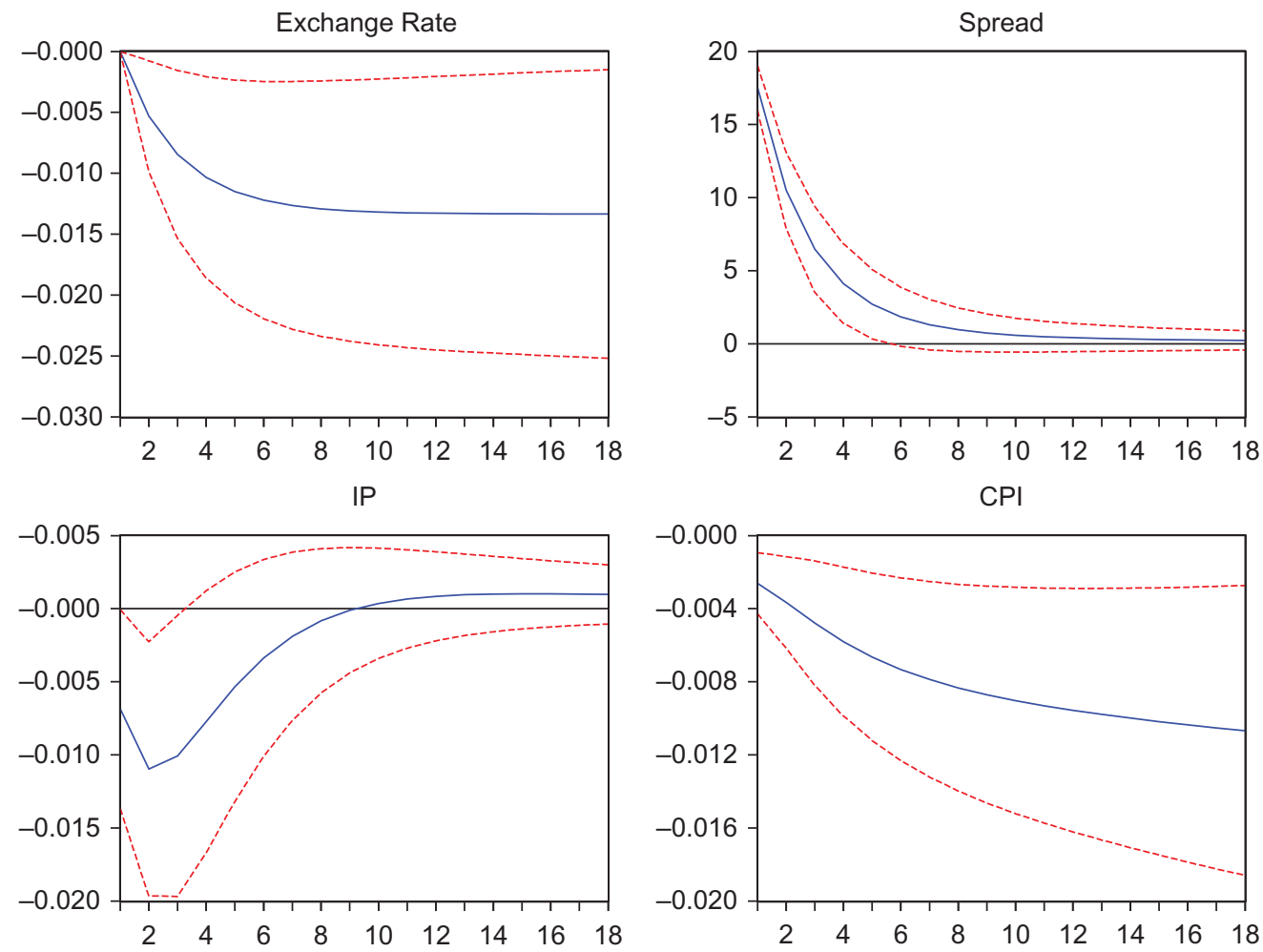

Fig. 2. Impulse responses to spread between interbank and Treasury auction interest rate shock: 1988:08-2011:07

Note: The middle line shows the impulse responses for 18 periods when a one-SD shock is given to the policy variable; the dotted lines are for \pm two-SE confidence bands.
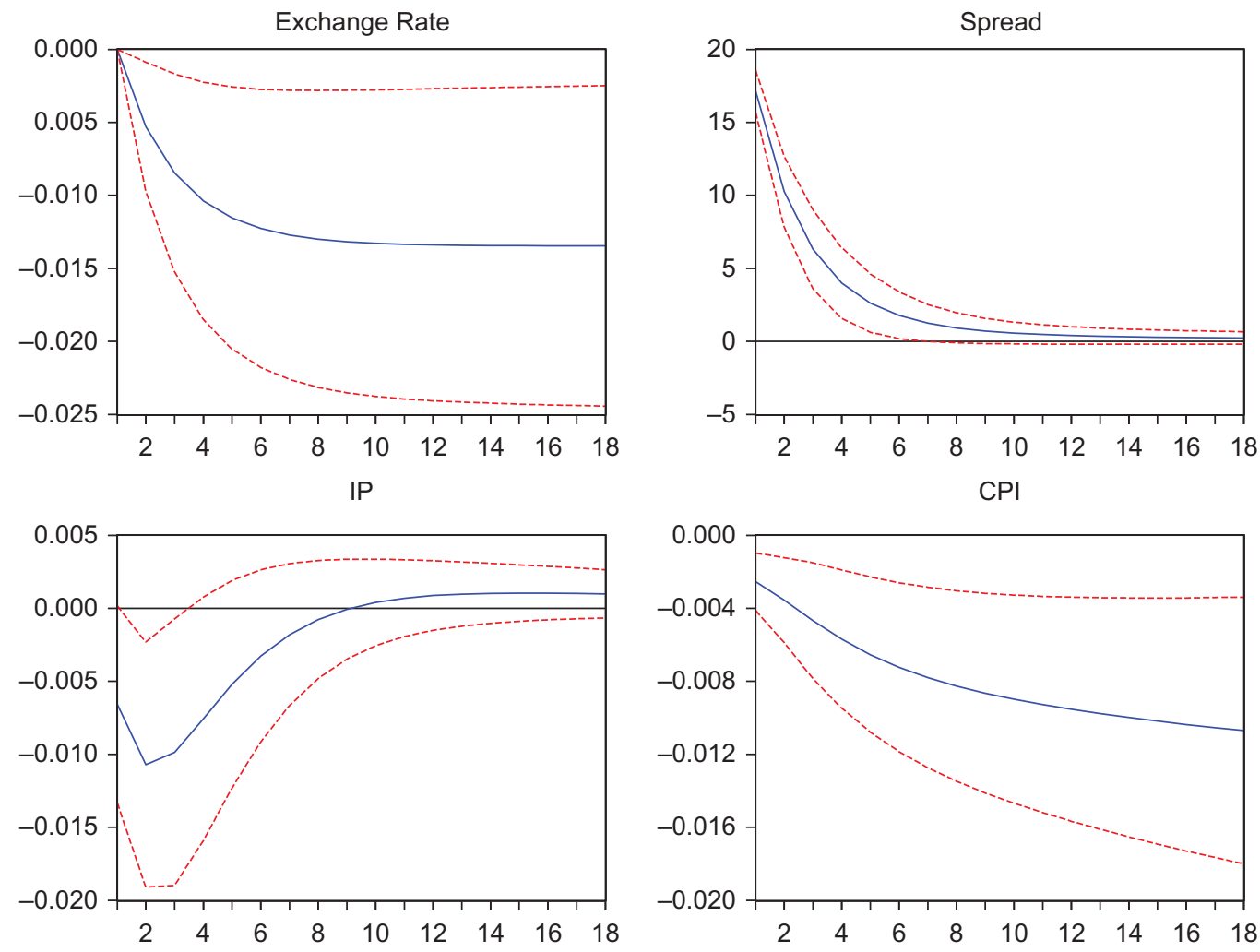

Fig. 3. Impulse responses to spread between interbank and Treasury auction interest rates shock: 1988:08-2012:07 Note: The middle line shows the impulse responses for 18 periods when a one-SD shock is given to the policy variable; the dotted lines are for \pm two-SE confidence bands. 

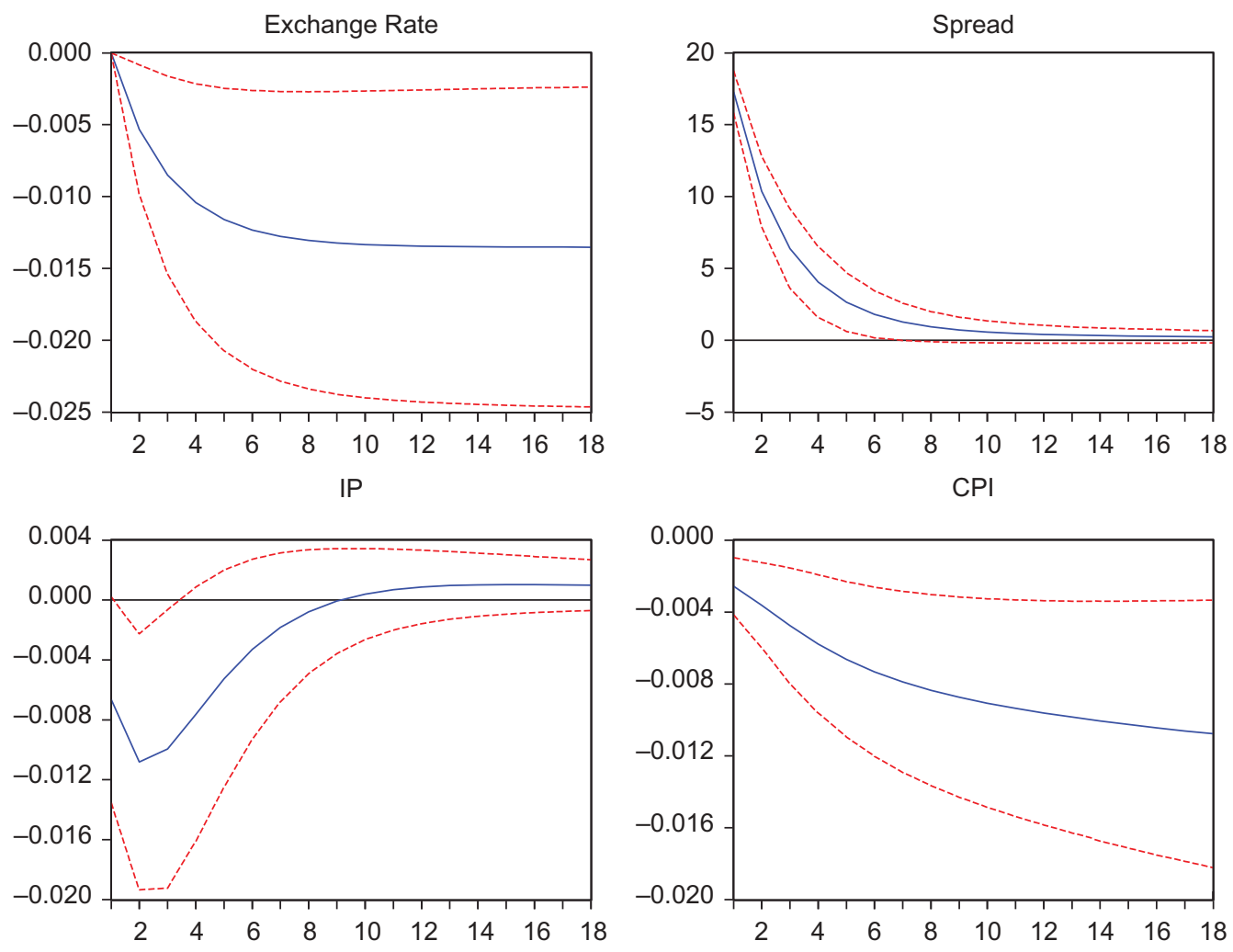

Fig. 4. Impulse responses to spread between the policy rate and Treasury auction rate shock: 1988:08-2012:07

Note: The middle line shows the impulse responses for 18 periods when a one-SD shock is given to the policy variable; the dotted lines are for \pm two-SE confidence bands.

exceptional days, we repeat the above exercise by replacing the funding rate (the official over-week policy rate, constant at 5.75) with the interbank rate after 2011:08, but also include an intercept dummy after this date. We report the results in Fig. 4. The estimates in Figs 4 and 5 are virtually unchanged.

To assess the role and effect on market liquidity level when there was a change in monetary policy, we include M2 as an additional variable in our benchmark VAR model (see Fig. 5). The higher the spread, the lower the output for six consecutive periods; this negative connection is statistically significant for at least three periods, in consistency with our benchmark specification. In coherence with the theoretical expectations, the amount of money also decreases, and is statistically significant for 16 months. A positive innovation of the spread also lowers exchange rate and decreases prices initially; however, these effects are not statistically significant.

We use the spread between the interbank rate and the Treasury auction interest rate as an identification restriction. It is plausible that both the interbank and Treasury rates affect economic performance in a nonparallel fashion; to account for this possibility, we enter these two variables separately. Figure 6 reports the corresponding impulse responses. A positive innovation in interbank rate increases (rather than decreases) exchange rate; thus the exchange rate puzzle exists. Second, a positive interest rate innovation increases (rather than decreases) prices; thus the price puzzle also exists. From these results we conclude that using positive innovations in the interbank rate solely as a policy tool or as an identifier of monetary policy tool is problematic.

By considering the CBRT's dual policy tool that had been used prior to 2001:03 (i.e., targeting the overnight interbank interest and exchange rates), Berument (2007) suggested using the spread between the interbank rate and the monthly depreciation rate of the Turkish Lira to identify the monetary policy. Hence, we replaced Treasury spread with exchange rate spread, and Fig. 7 shows the corresponding impulse responses. Unlike in our benchmark specification, we do not observe the exchange rate puzzle but we still see the price puzzle.

In order to account for the liquidity that the CBRT provides, Berument et al. (2011) employed an analogue of NBRs, which, unlike the US equivalent, includes the funding from FX market interventions to markets. The 

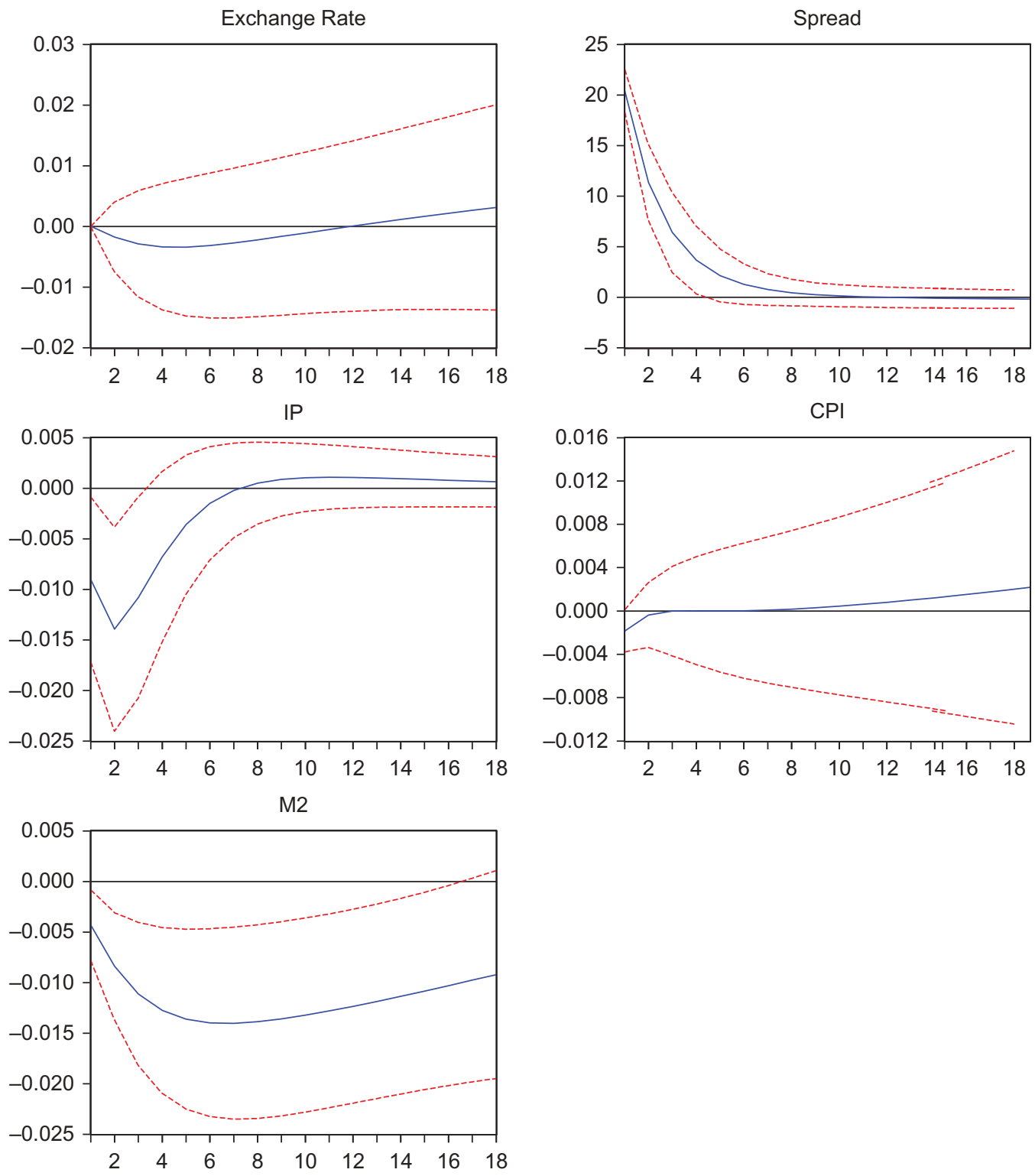

Fig. 5. Impulse responses to the spread between interbank rate and Treasury auction rate shock for a five-variable VAR specification, including $\mathrm{M} 2$

Note: The middle line shows the impulse responses for 18 periods when a one-SD shock is given to the policy variable; the dotted lines are for \pm two-SE confidence bands.

empirical evidence suggests that the new liquidity measure $(L)$ is not affected in a statistically significant fashion, and the impulses for the other variables are robust. The impulse response analyses for this specification and the remaining ones are not reported here to save space, but are available from the authors upon request. Moreover, Berument et al. (2011) successfully showed that $L$ can be taken as a measure of monetary policy in Turkey until 2010. Although we lack sufficient observations, we specify the model with one lag for the post-2010 era. When a one-SD shock to $L$ is given, not surprisingly most of the evidence is not statistically significant, but does indicate that a positive $L$ measure decreases but not increases prices. Last, we perform the analyses for the post-2002 era, that is, after the 2001 financial crisis. Similar issues prevail.

\section{Conclusion}

This article proposes that innovations in the spread between the CBRT's overnight rates and Treasury auction interest rates are informative for exchange rate, output, 

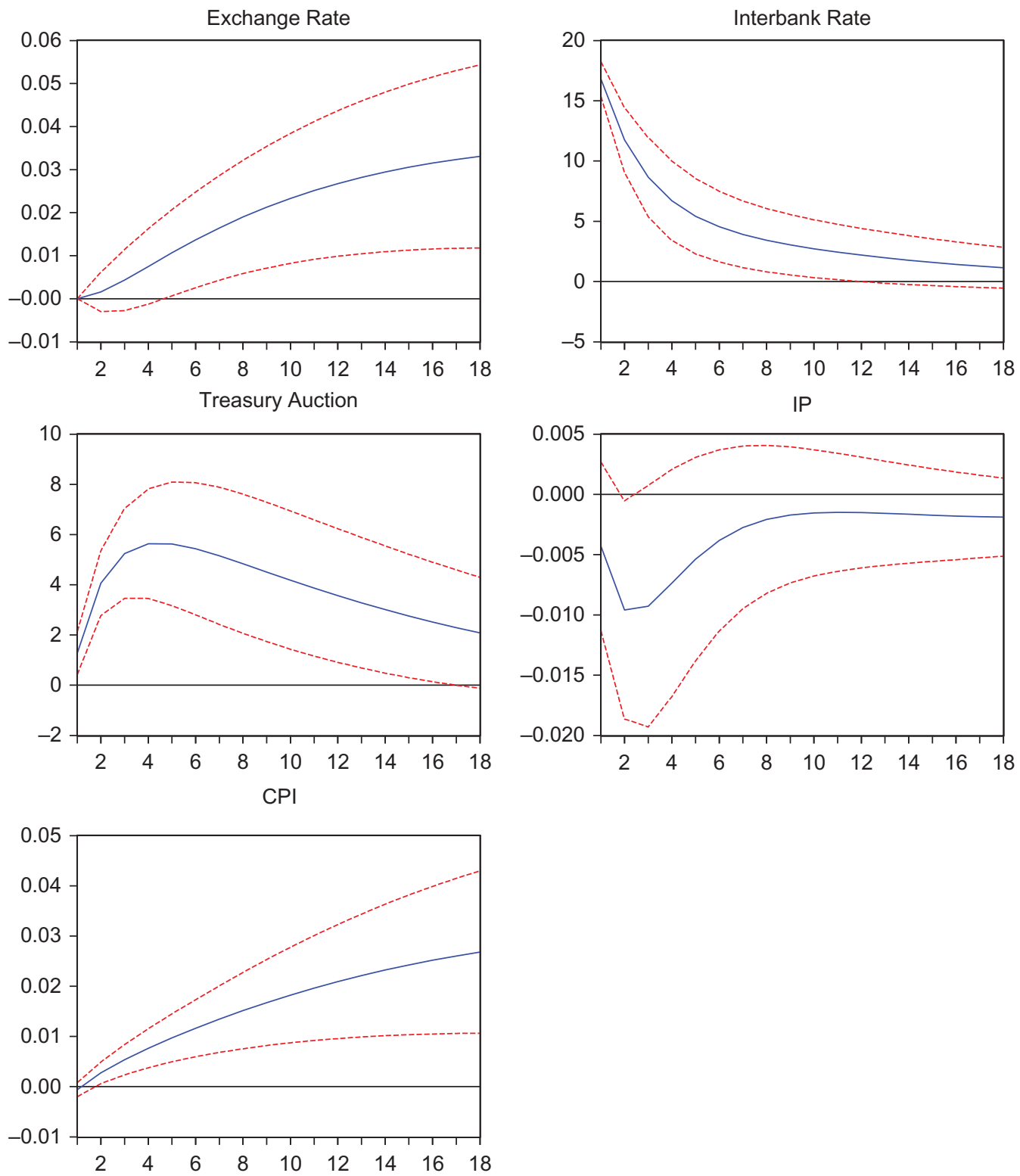

Fig. 6. Impulse responses to interest rate shocks

Note: The middle line shows the impulse responses for 18 periods when a one-SD shock is given to the interest rate; the dotted lines are for \pm two-SE confidence bands.

and prices in Turkey. In this manner, while the CBRT's overnight interest rate stands for the measure of the funding rate of the financial system's assets, the Treasury auction interest rate denotes a measure that the financial system can change in its assets in comparison with the funding rate. Tightness of monetary policy is implied by the size of the spread. That is, an increase in this measure can be taken as a measure of higher funding cost and therefore illiquidity.

The empirical evidence suggests that tight monetary policy measured by the spread defined herein decreases output temporarily and permanently appreciates local currency and decreases prices. This specification also eliminates the well-known exchange rate and price puzzles. The empirical evidence is robust for different specifications formed by including different relevant variables and for different sample sizes set according to the possible threshold dates representing radical policy shifts.

\section{Acknowledgement}

We would like to thank Rana Nelson and the anonymous referee for their helpful comments. 

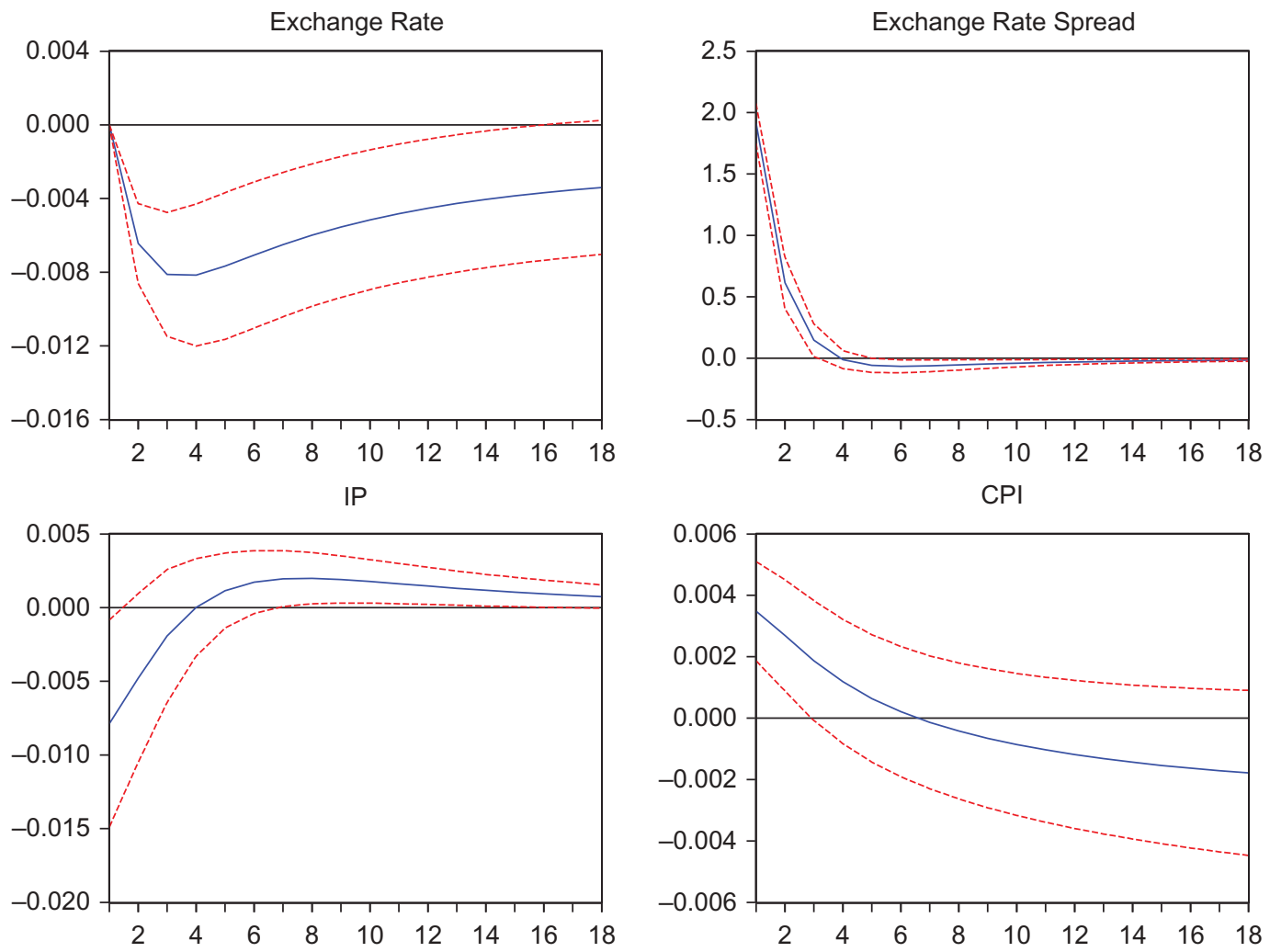

Fig. 7. Impulse responses to the spread between interest rate and depreciation spread shocks

Note: The middle line shows the impulse responses for 18 periods when a one-SD shock is given to the policy variable; the dotted lines are for \pm two-SE confidence bands.

\section{References}

Bernanke, B. S. (1990) On the predictive power of interest rates and interest rate spreads, New England Economic Review, November/December, 51-68.

Bernanke, B. S. and Mihov, I. (1998) Measuring monetary policy, Quarterly Journal of Economics, 113, 869-902.

Berument, H. (2007) Measuring monetary policy for a small open economy: Turkey, Journal of Macroeconomics, 29, 411-30.

Berument, H., Sahin, A. and Togay, S. (2011) Identifying the liquidity effects of monetary policy shocks for a small open economy: Turkey, Open Economies Review, 22, 649-67.

Berument, H. and Yucel, E. (2005) Return and maturity relationship for treasury auctions: theory and evidence from Turkey, Fiscal Studies, 26, 385-419.

Calvo, G. A. and Guidotti, P. E. (1992) Optimal maturity of nominal government debt: an infinite-horizon model, International Economic Review, 33, 895-919.

Christiano, L. J., Eichenbaum, M. and Evans, C. L. (1999) Monetary policy shocks: what have we learned and to what end?, in Handbook of Macroeconomics, Vol. 1A, Taylor, J. B. and Woodford, M. (Eds), Elsevier, NorthHolland, Amsterdam, pp. 65-145.

Friedman, B. M. and Kuttner, K. N. (1992) Money, income, prices and interest rates, American Economic Review, 82, 472-92.

Johnson, M. H. (1988) Current perspectives on monetary policy, Cato Journal, 8, 253-60.
Kim, S. and Roubini, N. (2000) Exchange rate anomalies in industrial countries: a solution with a structural VAR approach, Journal of Monetary Economics, 45, 561-86.

Laurent, R. D. (1988) An interest-rate based indicator of monetary policy, Economic Perspectives, 12, 3-14.

Leeper, E. M., Sims, C. A. and Zha, T. (1996) What does monetary policy do?, Brookings Papers on Economic Activity, 2, 1-63.

McCallum, B. T. (2005) Monetary policy and the term structure of interest rates, Federal Reserve Bank of Richmond Economic Quarterly, 91, 1-21.

Mishkin, S. F. (2011) Monetary policy strategy: lessons from the Crisis. NBER Working Papers, National Bureau of Economic Research, Inc. 16755, NBER, Cambridge, MA.

Missale, A. and Blanchard, O. J. (1994) The debt burden and debt maturity, American Economic Review, 84, 309-19.

Nautz, D. and Offermanns, C. J. (2008) Volatility transmission in the European money market, The North American Journal of Economics and Finance, Elsevier, 19, 23-39.

Sims, C. A. and Zha, T. (2006) Were there regime switches in US monetary policy?, American Economic Review, 96, $54-81$.

Stock, J. and Watson, M. W. (1989) New indexes of coincident and leading indicators, in NBER Macroeconomics Annual, Blanchard, O. and Fischer, S. (Eds), MIT Press, Cambridge, MA, pp. 351-93.

Woodford, M. (1994) Nonstandard indicators for monetary policy: can their usefulness be judged from forecasting regressions?, in Monetary Policy, Mankiw, N. (Ed), University of Chicago Press, Chicago, IL, pp. 95-116. 